\title{
Trypanocidal Potentials of Azadirachta indica: In Vivo Activity of Leaf Extract against Trypanosoma brucei brucei
}

\author{
Andrew J. NoK, ${ }^{1, *}$ King A.N. EsIEvo, ${ }^{2}$ Ishaya Longdet, ${ }^{1}$ \\ Samuel Arowosafe, ${ }^{1}$ Paul C. OnYeneKWE, ${ }^{3}$ \\ Casmir E. GimbA, ${ }^{4}$ and James A. KAGBU ${ }^{4}$ \\ ${ }^{1}$ Department of Biochemistry, ${ }^{2}$ Department of Veterinary Microbiology and Pathology, \\ ${ }^{3}$ Department of Plant Science, and ${ }^{4}$ Department of Chemistry, \\ Ahmadu Bello University, Zaria, Nigeria
}

(Received November 2, 1992)

\begin{abstract}
Summary An aqueous extract of defatted leaves of Azadirachta indica was found to possess trypanocidal activity against Trypanosoma brucei brucei. Column chromatography of the crude extract gave three fractions, I, II, and III, that eluted with ethylacetate/methanol, benzene/ methanol, and acetic acid/methanol, respectively. Of these extracts, only fraction III retained trypanocidal properties and cured mice chronically infected with Trypanosoma brucei brucei. Histopathological studies of the brains, livers, hearts, and spleens of the treated mice showed no cellular infiltrations. These findings are discussed in relation to trypanosome chemotherapy.
\end{abstract}

Key Words: Azadirachta indica, Trypanocidal activity, Trypanosoma brucei.

Trypanosomiasis is a parasitic disease prevailing in both humans and animals. It is caused by a single-cell parasite, Trypanosoma species. Some 35 million people and 25 million cattle in Africa are at risk of infection with trypanosomes [1]. In the case of chagas disease, the South American form of trypanosomiasis caused by Trypanosoma cruzi, there has been no completely suitable drugs for prevention or treatment $[2,3]$. The chemotherapy of trypanosomiasis is beset with problems, including a limited repertoire of compounds, resistance to drugs, drug toxicity, and protracted treatment protocols [4]. Moreover, there is no available trypanocidal drug that can be used routinely for the prevention of the disease during blood transfusion [5]. The inherent expensive nature of current trypanocides, coupled

*To whom correspondence should be addressed. 
with the side effects caused by the drugs, makes the sourcing of better trypanocides mandatory.

The Neem tree, Azadirachta indica, has been exploited for a long time as a potential source of traditional drugs. Several parts of the plant are known to have extensive medicinal application $[6,7]$. This common plant grows wild and thrives well even in harsh environments. Owing to the current interest in trypanosome chemotherapy, the need to explore cheaper and more accessible sources of trypanocides becomes imperative. It is in due consideration of the foregoing observations that this work was initiated with an interest to explore the trypanocidal potentials of Azadirachta indica.

\section{MATERIALS AND METHODS}

Material. A stabilate of pleomorphic Trypanosoma brucei brucei was obtained from the Department of Parasitology, Ahmadu Bello University, Nigeria. Twelve albino rats and twenty mice free from infection were purchased from the Department of Pharmacology, Ahmadu Bello University. Fresh leaves of Azadirachta indica were obtained from the Institute for Agricultural Research, Ahmadu Bello University. All other reagents used were of analytical grade and supplied by Sigma Chemical, Co., St. Louis, MO.

Extraction of crude flavonoids. The flavonoid extract was prepared as described [8]. Briefly, $40 \mathrm{~g}$ of the leaves were oven-dried at $60^{\circ} \mathrm{C}$ for $24 \mathrm{~h}$, grinded to a powder, and defatted in $200 \mathrm{ml}$ petroleum ether $\left(40-60^{\circ} \mathrm{C}\right)$. The mixture was then refluxed on a water bath for $1 \mathrm{~h}$ and filtered hot. The residue was dried at room temperature $\left(35^{\circ} \mathrm{C}\right)$ and refluxed in $200 \mathrm{ml}$ methanol for $2 \mathrm{~h}$. The methanol extract was concentrated under pressure in a rotary evaporator, and stored at $-10^{\circ} \mathrm{C}$. A portion of the residue $(0.8 \mathrm{~g})$ was dissolved in normal dextrose-saline $(10 \mathrm{ml})$, and $0.2 \mathrm{ml}$ of the preparation was used to inject each animal after infection.

Column chromatography. A slurry was prepared by dissolving $30 \mathrm{~g}$ silica gel in $100 \mathrm{ml}$ methanol: water $(1: 1)$, and packed in a column $(1.5 \times 30 \mathrm{~cm})$. The column was loaded with $15 \mathrm{ml}$ of the crude extract and sequentially eluted with ethylacetate/mathanol (19:1), benzene/methanol (9:1), and acetic acid/methanol $(1: 1)$. The fractions were collected separately, concentrated under pressure by rotary evaporation, and stored at $-10^{\circ} \mathrm{C}$. The recovered extracts from the column weighed $0.72,0.58$, and $0.55 \mathrm{~g}$ for fractions I, II, and III, respectively. Thin-layer chromatography (TLC) of the crude extract and of fraction III was performed on activated silica gel plates with ammonia solution : methanol $(1.5: 100)$ used as the developer. The plates were developed in iodine vapor.

Infection. Eight rats were infected by intraperitoneal inoculation of each with $10^{4}$ trypanosomes. Two uninfected rats ( $\mathrm{P}$ and $\left.\mathrm{W}\right)$, used as controls, were each given $1.0 \mathrm{ml}$ of normal dextrose-saline. The parasitemia was monitored for 6 days and followed by the intramuscular administration of $0.2 \mathrm{ml}$ of the crude flavonoid 
extract on day $7(80 \mathrm{mg} / \mathrm{kg} /$ day $)$ for 6 consecutive days to 6 infected rats. The other 2 infected rats $(\mathrm{G}$ and $\mathrm{H})$ were left untreated and served as a positive control. The trypanocidal effect was assessed by determining the level of parasitemia every 24 $\mathrm{h}$ post treatment. We film preparations from the tail blood were examined daily by the hemocytometer method [9].

Trypanocidal activity of fraction. Fifteen mice were each infected with $10^{4}$ trypanosomes and divided into 3 groups of 5. (Two control groups were used: X, infected, but not treated; and $\mathrm{Y}$, not infected.) The course of parasitemia was followed and treatment commenced on day 8 , when parasitemia was massive, by the intramuscular administration of $0.2 \mathrm{ml}$ of a dextrose-saline solution containing fraction I, II, or III (a dosage of $50 \mathrm{mg} / \mathrm{kg} /$ day), to members of groups $\mathrm{A}, \mathrm{B}$, and $\mathrm{C}$, respectively.

The chemoprophylaxis of each fraction was assessed as previously conducted [9].

Subinoculation experiments. Two treated rats and two mice in group C treated with fraction III were sacrificed 8 weeks post treatment. About $0.2 \mathrm{ml}$ of blood was recovered from each animal and used to inoculate 4 mice. Their kidneys, liver, spleen, and lymph of the sacrificed rats and mice (group C) were removed, washed, and grinded separately in normal dextrose-saline $(1: 2)$. About $0.2 \mathrm{ml}$ of each homogenate was used to inoculate a further 12 mice that were checked routinely for parasitemia for 8 weeks.

Cerebrospinal fluid (CSF). The hair at the back of the rat/mouse was shaved. The animal was positioned with its head touching its limbs, a posture making the vertebrae conspicuous. In this position, a needle was used to puncture the vertebrae between the third and fourth lumber. The fluid flowed into the needle and the first 3 drops discarded due to blood contamination. A syringe was then fixed to the needle and the CSF withdrawn. About $0.2 \mathrm{ml}$ of the CSF was used to inoculate 4 mice, and the presence of parasites was checked routinely.

Histopathology. Formalin fixed sections of the brain, spleen, liver, and heart were stained with hematoxylin and eosin to examine the presence of parasites and cellular infiltration.

\section{RESULTS AND DISCUSSION}

The crude extract of Azadirachta indica was found to possess trypanocidal activity toward Trypanosoma brucei brucei. Preliminary experiments showed that a dosage of $60 \mathrm{mg} / \mathrm{kg} /$ day of the crude resulted in parasitological cure of at least $65 \%$ mice infected with $10^{5}$ trypanosomes. Table 1 is a summary of the course of parasitemia before and after the commencement of treatment. The parasitemia in the infected rats was massive by day 6 , to about $10^{8}$ trypanosomes per $\mathrm{ml}$. After the administration of $80 \mathrm{mg} / \mathrm{kg} /$ day of the plant extract, a reduction in parasitemia was observed from day 3 of treatment in all the infected rats, and the infection was nil on the twelfth day post infection. There was still no visible parasite 30 days

Vol. 15, No. 2, 1993 
after the commencement of treatment (Table 1). That the trypanocidal effect is attributable to the plant extract is obvious, since members of the control group that were infected but not treated presented with massive parasitemia culminating into death 12 days post infection (Table 1).

It was then imperative to determine the active component(s) of the crude extract. Of the three fractions, I, II, and III, obtained from column chromatography and assessed for trypanocidal activity, only fraction III possessed the trypanocidal activity typified by the crude extract. This is easily observed by its ability to clear all the mice in group $\mathrm{C}$ of the bloodstream trypanosomes 5 days post treatment at a dosage of $50 \mathrm{mg} / \mathrm{kg} /$ day (Table 2). In an earlier experiment, 7 out of 11 mice (63.6\%) infected with Trypanosoma brucei brucei, were completely cured of the infection when given a dose of $25 \mathrm{mg} / \mathrm{kg} /$ day of fraction III for 12 days. The mice

Table 1. Course of parasitemia in the 8 infected rats $(A-H)$ for 6 days.

\begin{tabular}{lcccccccccc}
\hline \multirow{2}{*}{$\begin{array}{l}\text { Days post } \\
\text { infection }\end{array}$} & \multicolumn{7}{c}{ Number of parasites in the blood after infection } \\
\cline { 2 - 10 } & $\mathrm{A}$ & $\mathrm{B}$ & $\mathrm{C}$ & $\mathrm{D}$ & $\mathrm{E}$ & $\mathrm{F}$ & $\mathrm{G}$ & $\mathrm{H}$ & $\mathrm{P}$ & $\mathrm{W}$ \\
\hline and 2 & nil & nil & nil & nil & nil & nil & nil & nil & nil & nil \\
3 & $5.10^{3}$ & $10^{3}$ & $10^{3}$ & $10^{3}$ & $5.10^{3}$ & $10^{3}$ & $2.10^{3}$ & $10^{3}$ & nil & nil \\
4 & $10^{5}$ & $10^{5}$ & $10^{5}$ & $4.10^{5}$ & $6.10^{5}$ & $5.10^{4}$ & $10^{5}$ & $4.10^{5}$ & nil & nil \\
5 & $2.10^{6}$ & $6.10^{6}$ & $9.10^{7}$ & $6.10^{7}$ & $5.10^{8}$ & $5.10^{6}$ & $10^{5}$ & $4.10^{7}$ & nil & nil \\
6 & $10^{8}$ & $10^{8}$ & $10^{9}$ & $10^{8}$ & $10^{8}$ & $10^{8}$ & $10^{7}$ & $10^{8}$ & nil & nil \\
7 & $10^{9}$ & $10^{8}$ & $5.10^{9}$ & $4.10^{8}$ & $10^{8}$ & $5.10^{7}$ & $10^{7}$ & $10^{8}$ & nil & nil \\
8 & $10^{7}$ & $10^{8}$ & $10^{7}$ & $10^{6}$ & $10^{6}$ & $10^{7}$ & $10^{7}$ & $10^{7}$ & nil & nil \\
9 & $10^{7}$ & $10^{6}$ & $2.10^{5}$ & $4.10^{5}$ & $2.10^{5}$ & $10^{4}$ & $2.10^{8}$ & $10^{8}$ & nil & nil \\
10 & $10^{3}$ & $10^{3}$ & $5.10^{5}$ & $10^{3}$ & $10^{3}$ & $10^{3}$ & $10^{3}$ & Dead & nil & nil \\
11 & 50 & $10^{2}$ & nil & nil & $10^{2}$ & & & & nil & nil \\
12 & nil & nil & nil & nil & nil & & & & nil & nil \\
36 & nil & nil & nil & nil & nil & & & & nil & nil \\
\hline
\end{tabular}

Rats $\mathrm{P}$ and $\mathrm{W}$ were not infected. The treatment was commenced from day 7 after infection by the intramuscular administration of $0.2 \mathrm{ml}$ of the crude flavonoid in dextrose-saline ( 80 $\mathrm{mg} / \mathrm{kg} /$ day) to rats $\mathrm{A}$ to $\mathrm{F}$. Rats $\mathrm{G}$ and $\mathrm{H}$ were given same volume of normal dextrose-saline only and served as a control.

Table 2. Effect of the administration of fractions I, II, and III at a dosage of $50 \mathrm{mg} / \mathrm{kg} /$ day to 3 groups of the infected mice, A, B, and C, respectively.

\begin{tabular}{|c|c|c|c|c|c|c|c|}
\hline \multirow[b]{3}{*}{ Group } & \multicolumn{7}{|c|}{ Number of parasites in the blood after infection } \\
\hline & \multicolumn{7}{|c|}{ Period (days) } \\
\hline & 1 & 2 & 3 & 4 & 5 & 6 & 30 \\
\hline A & $(1 \pm 0.1) 10^{8}$ & $(1 \pm 0.2) 10^{7}$ & $(1 \pm 0.5) 10^{9}$ & Dead & & & \\
\hline B & $(6 \pm 0.6) 10^{8}$ & $(1 \pm 0.1) 10^{7}$ & $(5 \pm 0.5) 10^{8}$ & $(1 \pm 0.2) 10^{8}$ & Dead & & \\
\hline $\mathrm{C}$ & $(9 \pm 0.2) 10^{7}$ & $(1 \pm 0.05) 10^{7}$ & $(1 \pm 0.2) 10^{5}$ & $10^{2}$ & nil & nil & nil \\
\hline $\begin{array}{c}\mathrm{X} \\
\text { (positive cor }\end{array}$ & $(1 \pm 2) 10^{7}$ & $(1 \pm 0.3) 10^{9}$ & $(1 \pm 0.1) 10^{8}$ & Dead & & & \\
\hline $\begin{array}{c}\mathrm{Y} \\
\text { (negative co }\end{array}$ & ol) & nil & nil & nil & nil & nil & nil \\
\hline
\end{tabular}

Treatment was commenced 8 days post infection. 
in groups A and B failed to respond to the treatment with fractions I and II, respectively, even at concentrations between $250-300 \mathrm{mg} / \mathrm{kg} / \mathrm{day}$. The parasitemia in these groups along with that of the positive control (X) fulminated, resulting into the death of all the mice between days 4 and 6 after treatment. This observation is a good indication that the active ingredient of the Azadirachta indica crude extract is contained in fraction III.

Further analysis of fraction (III) along with the crude extract by thin-layer chromatography (TLC) revealed 2 spots, which were an exact match with 2 of the 4 spots observed for the crude extract. In the subinoculation experiments, we observed that none of the minced tissues from the treated mice produced parasitemia 14 weeks after inoculation. This presupposes that the parasites have been cleared from the systems and signifies the ability of the extract to be transported via the blood to the organs. However, the mice subinoculated with CSF started developing parasitemia 2 weeks after inoculation. Of considerable interest was that this group survived massive parasitemia 6 weeks post inoculation. This observation suggests the inability of the drug to cross the blood-brain-barrier to kill the parasites. The release of compounds from the CSF into the blood is a lot easier than the reverse [10]. The ability of a compound to cross the blood-brain-barrier depends on its ionization and lipid solubility. Thus the infectivity of the CSF can only be linked to the non entry of the extract into the CSF and not inactivity of the extract.

Even though there was no complete elimination of trypanosomes from the central nervous system (CNS), as exemplified by the infectivity of the CSF, the partial loss in parasite infectivity evidenced by the prolonged period to cause parasitemia is a good indication of the trypanocidal property of the extract. Since protein conjugates and immunoliposomes are in vogue as trypanocide delivery systems $[11,12]$, it may be possible to improve the trypanocidal efficacy of the Neem extract by coupling of the active factor with macromolecules that can readily cross the blood-brain-barrier. Histopathological studies conducted on sections of the brain, heart, liver, and spleen from the treated animals did not reveal parasites or cellular infiltrations suggestive of tissue parasitism or damage caused by the plant extract. Moreover, the leaf extract of Azadirachta indica has been shown not to have any toxicity in mammals. However, the seed oil extract is toxic, with an $\mathrm{LD}_{50}$ of $2.5 \mathrm{~g} / \mathrm{kg}[6,8]$.

From the accumulated information on the chemoprophylaxis of Azadirachta indica extract, and the interest in the sourcing of trypanocides from natural products [13-15], we recommend a further evaluation of this extract for trypanosome chemotherapy.

\section{REFERENCES}

1. Turner, M.J. (1982): Biochemistry of variant surface glycoproteins of salivarian trypanosomes. Adv. Parasitol., 21, 69-153.

Vol. 15, No. 2, 1993 
2. Decampo, R., and Moreno, S.N.J. (1984): Free radical metabolites in the mode of action of chemotherapeutic agents and phagocytic cells in Trypanosoma cruzi. Rev. Infect. Dis., 6 , 223-228.

3. Nicholas, J., Murgolo, A.C., and Graeme, B.H. (1989): Trypanothione reductase. Ann. NY Acad. Sci., 569, 193-218.

4. Tropical disease Research, 7th Programme Report, 1 January, 1983-31 December, 1984: Chap 5, 3-19. United Nations Development Programme/World/Bank/World Health Organisation.

5. Gutteridge, W.E. (1985): Existing chemotherapy and its limitations. Br. Med. Bull., 41, $162-168$.

6. Lewis, W.H., and Elvin-Lewis, M.P.F. (1977): Medical Botany (2nd ed.), John Wiley, New York, $246 \mathrm{pp}$.

7. Okpanyi, S.N., and Ezenkwu, G.C. (1981): Anti-inflammatory and anti-pyretic activities of Azadirachta indica. Planta Med., 4, 44-45.

8. Nwude, N., Chinemo, C.N., and Araja, J.A. (1983): Acute and chronic toxicity of Azadirachta indica in mice and rats. Niger. J. Pharmacol., 9, 6-7.

9. Herbert, W.J., and Lumsden, W.H.R. (1976): Trypanosoma brucei. A rapid matching method for estimating the host parasitemia. Exp. Parasitol., 40, 427-431.

10. Pappenheimer, J., Heissey, S., and Jordan, E. (1961): The blood-brain-barrier, in Selective Toxicity (2nd ed.), ed. by Adrien, A., John Wiley \& Sons, New York, pp. 54-65.

11. Mitchell, J.B. (1989): Protein conjugates as trypanocide delivery systems, in Chemotherapy of Trypanosomiasis. Proceedings of a Workshop Held at ILRAD Nairobi, Kenya, 23-24 August 1989, pp. 115-118.

12. Rouse, B.T., Kennell, S.J., and Huang, L. (1989): Drug delivery by immunoliposomes, in Chemotherapy for Trypanosomiasis. Proceedings of a Workshop Held at ILRAD Nairobi, Kenya, 23-24 August 1989, pp. 119-122.

13. Gonzalez, J., Pereira, J., Estrada, M., Araya, J., Saguar, H., Loyola, L., and Morales, G. (1989): Trypanosoma cruzi: In vivo evaluation of Trypanocidal action of natural product of vegetable origin. Mem. Inst. Oswaldo Cruz (Rio de Janeiro), Suppl. 81, 154.

14. Owolabi, O.A., Makanga, B., Thomas, E.W., Molyneux, D.H., and Oliver, R.W. (1990): Trypanocidal potentials of African woody plant: In vitro trial of Khaya grandifoliola seed extracts. J. Ethnopharmacol, 30 227-231. 